Article

\title{
Physicochemical Characterization, Antioxidant and Immunostimulatory Activities of Sulfated Polysaccharides Extracted from Ascophyllum nodosum
}

\author{
Ligen Chen ${ }^{1,2,3}$, Yan Wang ${ }^{1}$, Hui Yang ${ }^{2}$, Han Li ${ }^{1,2,3}$, Wei Xu ${ }^{2,3, *}$, Guijie Chen 4 (i) \\ and Hongjun $\mathrm{Zhu}{ }^{1, *}$ \\ 1 College of Chemistry and Molecular Engineering, Nanjing Tech University, Nanjing 211816, China; \\ chenlg@ycit.cn (L.C.); $1954357344 @$ jutech.edu.cn (Y.W.); zllz@ycit.cn (H.L.) \\ 2 School of Marine and Bioengineering, Yancheng Institute of Technology, Yancheng 224051, China; \\ yangh96@yahoo.com \\ 3 Jiangsu Key Laboratory of Biochemistry and Biotechnology of Marine Wetland, Yancheng Institute of Technology, \\ Yancheng 224051, China \\ 4 College of Food Science and Technology, Nanjing Agricultural University, Nanjing 210095, China; \\ guijiechen@njau.edu.cn \\ * Correspondence: xuweiyc@163.com (W.X.); zhuhj@njtech.edu.cn (H.Z.); Tel.: +86-515-88298179 (W.X.); \\ +86-25-83172358 (H.Z.); Fax: +86-25-83587428 (H.Z.)
}

Received: 5 July 2018; Accepted: 26 July 2018; Published: 31 July 2018

\begin{abstract}
Polysaccharides from Ascophyllum nodosum (AnPS) were extracted and purified via an optimized protocol. The optimal extraction conditions were as follows: extraction time of $4.3 \mathrm{~h}$, extraction temperature of $84{ }^{\circ} \mathrm{C}$ and ratio $(v / w, \mathrm{~mL} / \mathrm{g})$ of extraction solvent (water) to raw material of 27 . The resulting yield was $9.15 \pm 0.23 \%$ of crude AnPS. Two fractions, named AnP1-1 and AnP2-1 with molecular weights of $165.92 \mathrm{KDa}$ and $370.68 \mathrm{KDa}$, were separated from the crude AnPS by chromatography in DEAE Sepharose Fast Flow and Sephacryl S-300, respectively. AnP1-1 was composed of mannose, ribose, glucuronic acid, glucose and fucose, and AnP2-1 was composed of mannose, glucuronic acid, galactose and fucose. AnPS, AnP1-1 and AnP2-1 exhibited high scavenging activities against ABTS radical and superoxide radical, and showed protective effect on $\mathrm{H}_{2} \mathrm{O}_{2}$-induced oxidative injury in RAW264.7 cells. Furthermore, the immunostimulatory activities of AnP1-1 and AnP2-1 were evaluated by Caco-2 cells, the results showed both AnP1-1 and AnP2-1 could significantly promote the production of immune reactive molecules such as interleukin (IL)-8, IL-1 $\beta$, interferon (IFN)- $\gamma$, and tumor necrosis factor (TNF)- $\alpha$. Therefore, the results suggest that AnPS and its two fractions may be explored as a potential functional food supplement.
\end{abstract}

Keywords: Ascophyllum nodosum; polysaccharides; antioxidant activity; immunostimulatory activity

\section{Introduction}

Edible marine macroalgae, or seaweeds, products have been traditionally used in Chinese herbal medicine for more than 600 years [1]. Marine macroalgae are commonly classified into three groups based on their pigmentation: brown (Phaeophyceae), red (Rhodophyceae) and green (Chlorophyceae) algae [2]. Ascophyllum nodosum is one of the most economically important brown algae in Britain, Peru and many other countries [3]. Compared with red and green algae, brown algae were reported to contain higher content of active components and showed stronger antioxidant activity [4]. The major components of brown algae extracts are polysaccharides, phenolic compounds, proteins, pigments, peptides, polyunsaturated fatty acids and terpenoids [5]. Recently, increasing attentions have been paid to brown algae polysaccharides due to their pharmacological activities, such as anticoagulant, 
antitumor, immunomodulatory, antiviral, antihyperlipidemic and antioxidant activity [6-9]. A growing body of evidences has demonstrated that the immunostimulatory activity is one of the most important biological activities of polysaccharides, which may serve as an important mechanism for its antitumor effect [10]. Intestine is an important immune organ of the human body. Non-starch polysaccharides can resist the digestion and hydrolyzation in the human saliva, stomach and small intestine [11], which thus reaches the intestine safely, where they may act as potential immune stimulator. Yu et al. [12] reported that EPS1-1, extracted from the fermentation broth of Rhizopus nigricans, was an extracellular polysaccharide, which play an important role in the improvement of intestinal function in mice with colorectal cancer. Kim et al. [13] reported that BLE-P, isolated from barley leaves, was a mixture of hemicellulosic glucuronoarabinoxylan and pectic rhamnogalacturonan. The results indicated that BLE-P not only augmented the production of immunoglobulin A (IgA), but also increased the levels of IgA-related cytokines, such as transforming growth factor-b and interleukin-10. Brito et al. [14] reported that PLS, extracted from the algae Hypnea musciformis, was sulfated polysaccharides, which reduced the colitis and all analyzed biochemical parameters. However, few reports were focus on the intestinal immunostimulatory activities of sulfated polysaccharides from Ascophyllum nodosum and the separation and characterization of polysaccharides from Ascophyllum nodosum [3]. To the best of our knowledge, this is the first attempt to investigate the antioxidant activities of different fractions from crude AnPS.

In this study, Ascophyllum nodosum was selected as the representative of brown algae, which was reported to contain much higher total polysaccharide than that of other bioactive compounds. The conditions required to extract polysaccharides from Ascophyllum nodosum were explored by means of response surface methodology (RSM) on the basis of a Box-Behnken design (BBD). The predicted conditions were used to purify the AnPS by DEAE Fast Flow cellulose anion-exchange column and Sephacryl S-300 size exclusion column. The obtained fractions, AnP1-1 and AnP2-1, were characterized by FT-IR and HPLC. The antioxidant activities of AnPS, AnP1-1 and AnP2-1 were evaluated in ABTS, DPPH radical scavenging, superoxide anion radical scavenging and reducing power assays. The protective effect on $\mathrm{H}_{2} \mathrm{O}_{2}$-induced oxidative injury in RAW264.7 cells was investigated. Furthermore, the intestinal immunostimulatory activities of the two fractions were also examined for the first time.

\section{Results and Discussion}

\subsection{Optimization of AnPS Extraction Conditions}

The experiment design for extraction yield is shown in Table 1, and the results were analyzed using Design-Expert 8.0.6 software. The relationship between the independent variables and the dependent variables was described by the following second-order polynomial equation [15]:

$$
Y=9.01+0.70 X_{1}+0.18 X_{2}+0.62 X_{3}+0.015 X_{1} X_{3}-0.91 X_{1}^{2}-0.33 X_{2}^{2}-0.83 X_{3}^{2}
$$

where $X_{1}, X_{2}$ and $X_{3}$ represents extraction temperature, extraction time and ratio of water to raw material, respectively.

Table 1. Box-Behnken design matrix and the response values for the extraction yield of AnPS.

\begin{tabular}{ccccccccc}
\hline \multirow{2}{*}{ Run } & \multicolumn{2}{c}{ Temperature $\left({ }^{\circ} \mathbf{C}\right)$} & Time (h) & \multicolumn{2}{c}{$\begin{array}{c}\text { Ratio of Water to } \\
\text { Raw Material (mL/g) }\end{array}$} & $\begin{array}{c}\text { Predicted } \\
\text { Value (\%) }\end{array}$ & $\begin{array}{c}\text { Experimental } \\
\text { Value (\%) }\end{array}$ \\
\cline { 2 - 6 } & $\mathbf{X}_{\mathbf{1}}$ & Code $\mathbf{X}_{\mathbf{1}}$ & $\mathbf{X}_{\mathbf{2}}$ & Code $\mathbf{X}_{\mathbf{2}}$ & $\boldsymbol{X}_{\mathbf{3}}$ & Code $\mathbf{X}_{\mathbf{3}}$ & & \\
\hline $\mathbf{1}$ & 80 & 0 & 4 & 0 & 25 & 0 & 9.01 & 9.09 \\
$\mathbf{2}$ & 90 & 1 & 4 & 0 & 20 & -1 & 7.34 & 7.22 \\
$\mathbf{3}$ & 70 & -1 & 5 & 1 & 25 & 0 & 7.26 & 7.32 \\
$\mathbf{4}$ & 70 & -1 & 3 & -1 & 25 & 0 & 6.89 & 6.85 \\
\hline
\end{tabular}


Table 1. Cont.

\begin{tabular}{ccccccccc}
\hline \multirow{2}{*}{ Run } & \multicolumn{2}{c}{ Temperature $\left({ }^{\circ} \mathbf{C}\right)$} & \multicolumn{2}{c}{ Time (h) } & \multicolumn{2}{c}{$\begin{array}{c}\text { Ratio of Water to } \\
\text { Raw Material } \mathbf{( m L} / \mathbf{g})\end{array}$} & $\begin{array}{c}\text { Predicted } \\
\text { Value (\%) }\end{array}$ & $\begin{array}{c}\text { Experimental } \\
\text { Value (\%) }\end{array}$ \\
\cline { 2 - 6 } & $\mathbf{X}_{\mathbf{1}}$ & Code $\mathbf{X}_{\mathbf{1}}$ & $\mathbf{X}_{\mathbf{2}}$ & Code $\mathbf{X}_{\mathbf{2}}$ & $\mathbf{X}_{\mathbf{3}}$ & Code $\mathbf{X}_{\mathbf{3}}$ & & \\
\hline $\mathbf{5}$ & 80 & 0 & 4 & 0 & 25 & 0 & 9.01 & 8.90 \\
$\mathbf{6}$ & 80 & 0 & 5 & 1 & 30 & 1 & 8.65 & 8.47 \\
$\mathbf{7}$ & 70 & -1 & 4 & 0 & 30 & 1 & 7.17 & 7.29 \\
$\mathbf{8}$ & 80 & 0 & 3 & -1 & 30 & 1 & 8.28 & 8.20 \\
$\mathbf{9}$ & 80 & 0 & 3 & -1 & 20 & -1 & 7.05 & 7.23 \\
$\mathbf{1 0}$ & 90 & 1 & 4 & 0 & 30 & 1 & 8.61 & 8.75 \\
$\mathbf{1 1}$ & 70 & -1 & 4 & 0 & 20 & -1 & 5.96 & 5.82 \\
$\mathbf{1 2}$ & 80 & 0 & 4 & 0 & 25 & 0 & 9.01 & 8.85 \\
$\mathbf{1 3}$ & 80 & 0 & 4 & 0 & 25 & 0 & 9.01 & 9.04 \\
$\mathbf{1 4}$ & 80 & 0 & 4 & 0 & 25 & 0 & 9.01 & 9.17 \\
$\mathbf{1 5}$ & 80 & 0 & 5 & 1 & 20 & -1 & 7.41 & 7.49 \\
$\mathbf{1 6}$ & 90 & 1 & 5 & 1 & 25 & 0 & 8.65 & 8.69 \\
$\mathbf{1 7}$ & 90 & 1 & 3 & -1 & 25 & 0 & 8.29 & 8.23 \\
\hline
\end{tabular}

ANOVA was used to determine significance and suitability in the model (Table 2). The result indicated that the $F$-value of the model is 49.98 with a low probability $p$-value $(<0.0001)$, which implied that the model was significant. The values of both the determination coefficient $\left(R^{2}=0.9847\right)$ and the adjusted determination coefficient $\left(\right.$ adj- $R^{2}=0.9651$ ) were high, which suggested good agreement between the experimental and the predicted values of the AnPS yield. The results suggested that the extraction temperature $\left(\mathrm{X}_{1}\right)$ was the most significant parameter affecting the yield of AnPS, followed by extraction time $\left(X_{2}\right)$ and ratio of water to raw material $\left(X_{3}\right)$.

Table 2. ANOVA for response surface quadratic model of AnPS extraction.

\begin{tabular}{cccccc}
\hline Source & Sum of Squares & DF & Mean Square & F-Value & $p$-Value \\
\hline Model & 14.77 & 9 & 1.64 & 49.98 & $<0.0001$ \\
$\mathrm{X}_{1}$ & 3.93 & 1 & 3.93 & 119.77 & $<0.0001$ \\
$\mathrm{X}_{2}$ & 0.27 & 1 & 0.27 & 8.11 & 0.0248 \\
$\mathrm{X}_{3}$ & 3.06 & 1 & 3.06 & 93.25 & $<0.0001$ \\
$\mathrm{X}_{1} \mathrm{X}_{2}$ & 0 & 1 & 0 & 0 & 0.9788 \\
$\mathrm{X}_{1} \mathrm{X}_{3}$ & 0 & 1 & 0 & 0.027 & 0.8732 \\
$\mathrm{X}_{2} \mathrm{X}_{3}$ & 0 & 1 & 0 & 0 & 0.9788 \\
$\mathrm{X}_{1}{ }^{2}$ & 3.47 & 1 & 3.47 & 105.57 & $<0.0001$ \\
$\mathrm{X}_{2}^{2}$ & 0.46 & 1 & 0.46 & 13.96 & 0.0073 \\
$\mathrm{X}_{3}{ }^{2}$ & 2.92 & 1 & 2.92 & 88.84 & $<0.0001$ \\
Residual & 0.23 & 7 & 0.033 & & \\
Lack of fit & 0.16 & 3 & 0.053 & 3.01 & 0.1575 \\
Pure error & 0.071 & 4 & 0.018 & & \\
Cor. total & 15 & 16 & & & \\
\hline
\end{tabular}

Figure $1 \mathrm{~A}, \mathrm{D}$, depict the changes in extraction yield when the extraction temperature and extraction time varied across the experimental range when the ratio of water to raw material was fixed at zero. The yield is predicted to increase as the extraction temperature is elevated from 50 to $80^{\circ} \mathrm{C}$. At higher temperatures, the yield is predicted to slightly decrease. Generally, higher extraction temperature can promote the release of polysaccharides from plant tissues, but further increases in extraction temperature may induce polysaccharide degradation [16]. A similar trend was also predicted when extraction time and ratio of water to raw material were varied, as shown in Figure 1B,C. 
(A)

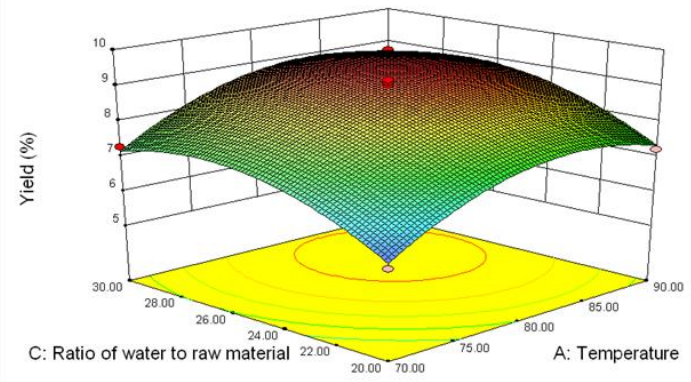

(B)

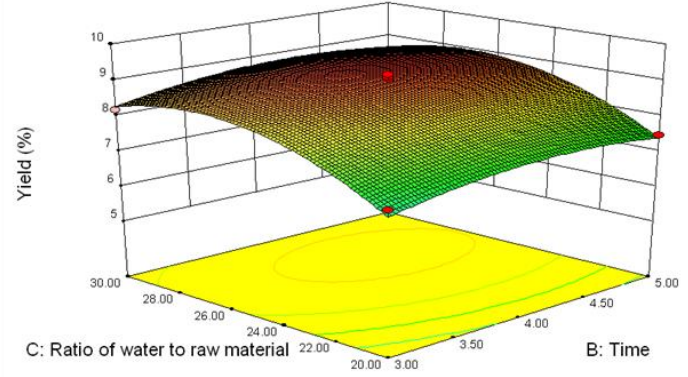

(C)

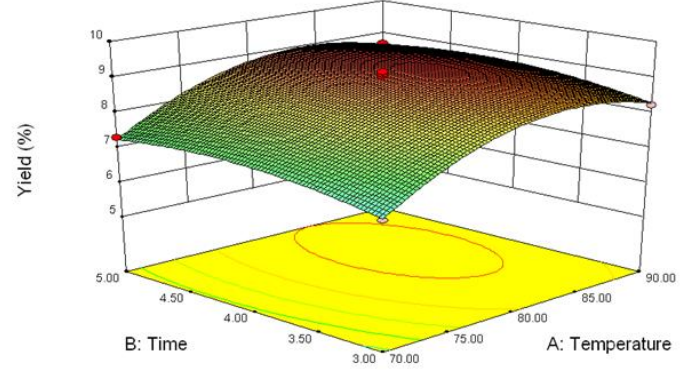

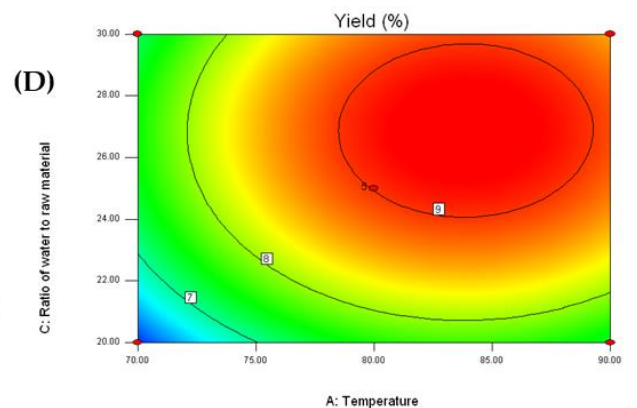

(E)

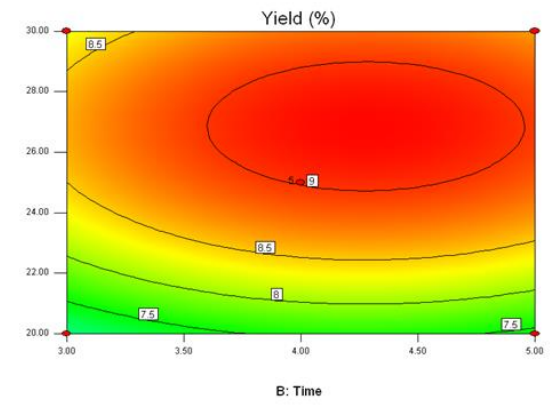

(F)

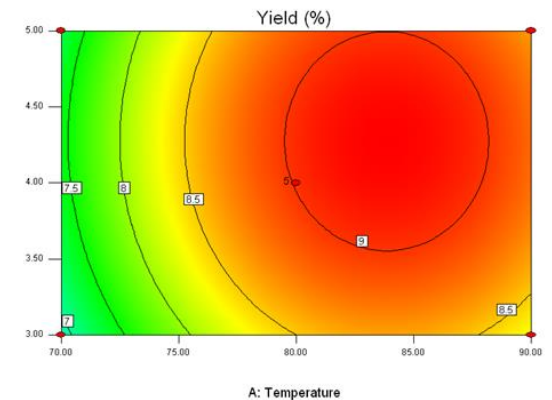

Figure 1. Response surface plots (A-C) and contour plots (D-F) showing the effects of two varied parameters (extraction temperature, extraction time, ratio of water to material) on the extraction yield of Ascophyllum nodosum polysaccharides (AnPS).

According to the above RSM results, the optimal extraction conditions were obtained as follow: Extraction temperature of $83.9^{\circ} \mathrm{C}$, extraction time of $4.3 \mathrm{~h}$, and a ratio of water to raw material of $26.9 \mathrm{~mL} / \mathrm{g}$. Under these conditions, the maximum predicted yield of AnPS was 9.3\%. To validate the RSM model, a verification experiment was carried out under the optimized conditions, affording a AnPS yield of $9.2 \pm 0.23 \%(n=3)$. Notably, the yield of AnPS was higher than that of some polysaccharides $(2.84-6.81 \%)$ from other brown seaweeds $[17,18]$. The result suggested that the conditioned modeled by RSM could be used in practice for the extraction of polysaccharides from Ascophyllum nodosum.

\subsection{Isolation and Purification of Polysaccharide Fraction AnP1-1 and AnP2-1}

The crude AnPs was purified by DEAE Sepharose Fast Flow via a gradient elution of 0-1.5 M $\mathrm{NaCl}$ into two independent fractions (AnP1 and AnP2) as showed in Figure 2A. The peaks AnP1 and AnP2 were further purified by Sephacryl S-300 size exclusion chromatography using $0.1 \mathrm{M} \mathrm{NaCl}$ as the mobile phase (Figure 2B,C) to obtain the fractions of AnP1-1 and AnP2-1. 
(A)

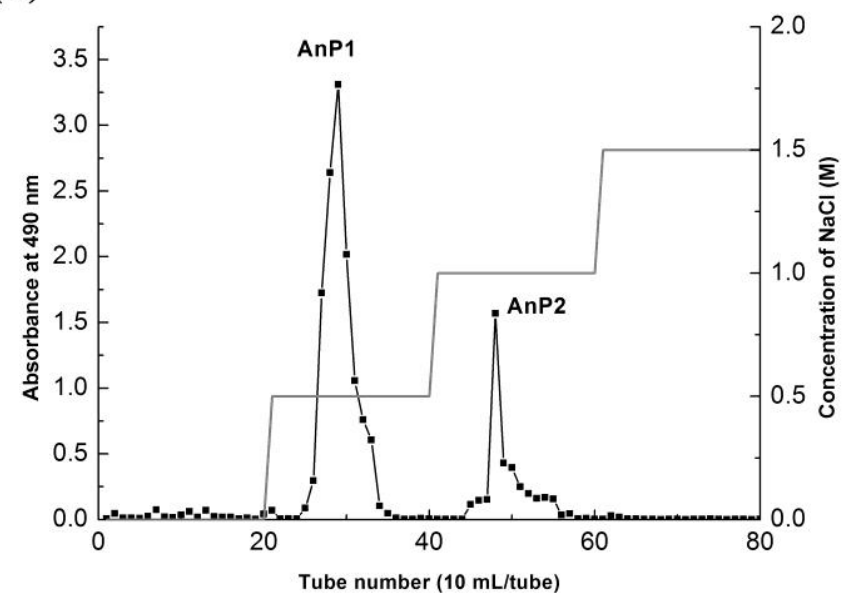

(B)

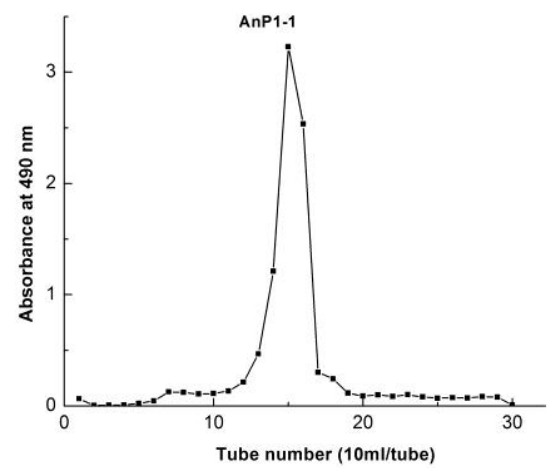

(C)

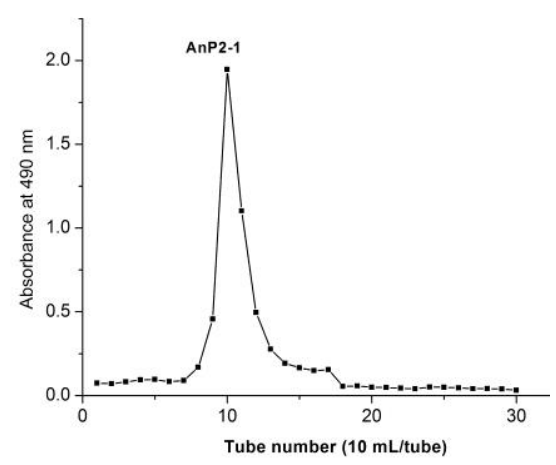

Figure 2. Stepwise elution curve of crude AnPS on DEAE Fast Flow column (A) and elution curves of polysaccharide fractions AnP1-1 (B), AnP2-1 (C) on Sephacryl S-300 column.

\subsection{Characterization, Molecular Weight and Monosaccharide Composition of AnP1-1 and AnP2-1}

The contents of carbohydrate, protein, total polyphenols, uronic acid and sulfate group in the AnPS, AnP1-1 and AnP2-1 fractions are shown in Table 3. The contents of carbohydrate in AnPS, AnP1-1 and AnP2-1 were 42.3\%, 26.6\% and 36.7\%, respectively. The contents of protein in AnPS and its fractions were very low $(1.4 \%, 0.5 \%$ and $0.4 \%$ for AnPS, AnP1-1 and AnP2-1, respectively). The total polyphenols content of crude AnPS (2.11 GAE/100 mg) was higher than that of AnP1-1 (0.13 GAE/100 mg) and AnP2-1 (0.11 GAE/100 mg), indicating that most of the polyphenols in AnPS was removed after the purification. The contents of uronic acid in AnPS, AnP1-1 and AnP2-1 were $11.0 \%, 13.5 \%$ and $3.6 \%$, respectively. The contents of sulfate groups in AnPS, AnP1-1 and AnP2-1 were $23.9 \%, 5.4 \%$ and $23.8 \%$, indicating that they should be sulfated polysaccharides.

Table 3. Preliminary characterization of AnPS, AnP1-1 and AnP2-1.

\begin{tabular}{cccc}
\hline Item & AnPS & AnP1-1 & AnP2-1 \\
\hline Carbohydrate (\%) & $42.31 \pm 1.12$ & $26.55 \pm 1.12$ & $36.69 \pm 0.03$ \\
Protein (\%) & $1.43 \pm 0.02$ & $0.53 \pm 0.01$ & $0.42 \pm 0.04$ \\
Total polyphenols (mg GAE/100 mg) & $2.11 \pm 0.04$ & $0.13 \pm 0.01$ & $0.11 \pm 0.01$ \\
Uronic acid (\%) & $11.04 \pm 0.23$ & $13.53 \pm 0.79$ & $3.56 \pm 0.80$ \\
sulfate group (\%) & $23.9 \pm 0.07$ & $5.4 \pm 0.11$ & $23.8 \pm 0.02$ \\
Molecular weight (kDa) & - & 165.92 & 370.68 \\
Monosaccharide composition (mol) & & & \\
Man & 1 & 1 & 1 \\
Rib & - & 0.40 & -
\end{tabular}


Table 3. Cont.

\begin{tabular}{cccc}
\hline Item & AnPS & AnP1-1 & AnP2-1 \\
\hline GlcA & 1.22 & 0.45 & 1.50 \\
Glc & 0.10 & 0.32 & - \\
Gal & 0.58 & - & 1.39 \\
Xyl & 0.21 & & \\
Fuc & 2.90 & 3.44 & 8.32 \\
\hline
\end{tabular}

-: Not detected.

The molecular weights of AnP1-1 and AnP2-1 were evaluated by HPGPC, and single and symmetrical peaks were detected, indicating that they are homogeneous polysaccharide. The average molecular weight of AnP1-1 was calculated to be $165.92 \mathrm{KDa}$ and of AnP2-1 to be $370.68 \mathrm{KDa}$, according to the standard D-series dextrans.

The monosaccharide composition of AnPS, AnP1-1 and AnP2-1 were analyzed by HPLC (Table 3). AnPS was composed of Man, GlcA, Glc, Gal, $\mathrm{Xyl}$ and Fuc in the molar ratio of 1:1.22:0.10:0.58:0.21:2.90. AnP1-1 was composed of Man, Rib, GlcA, Glc and Fuc in the molar ratio of 1:0.40:0.45:0.32:3.44. AnP2-1 was mainly composed of Man, GlcA, Gal and Fuc in the molar ratio of 1:1.50:1.39:8.32. The results indicated that AnPS, AnP1-1 and AnP2-1 were heteropolysaccharides, and the fucose was the major monosaccharide.

\subsection{FT-IR Analysis}

The FT-IR spectra of AnPS (A) and its purified fractions, AnP1-1 (B) and AnP2-1 (C), are shown in Figure 3. The broad and strong absorption peak around $3400 \mathrm{~cm}^{-1}$ could be attributed to $\mathrm{O}-\mathrm{H}$ stretching vibrations, and a weak peak at about $2900 \mathrm{~cm}^{-1}$ could be attributed to C-H stretching vibrations. The band of at $1606 \mathrm{~cm}^{-1}$ and $1414 \mathrm{~cm}^{-1}$ was assigned to the COO- antisymmetrical stretching band and $\mathrm{C}=\mathrm{O}$ symmetric stretching vibration of the carboxylate group of uronic acid.

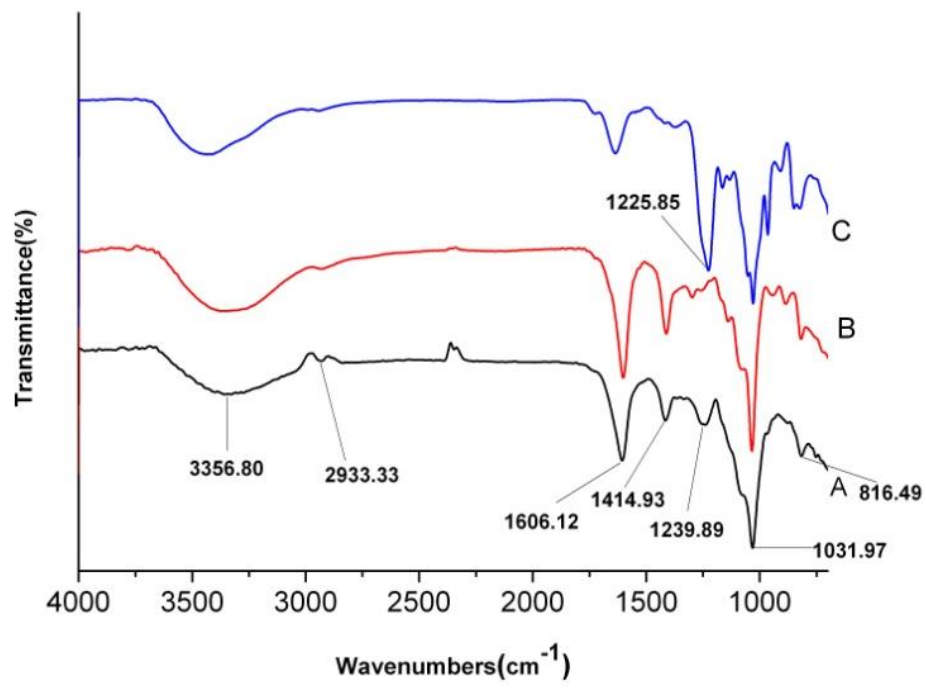

Figure 3. FT-IR spectra of AnPS (A), AnP1-1 (B) and AnP2-1 (C).

Compared with $\mathrm{C}$, the band at $1606 \mathrm{~cm}^{-1}$ and $1414 \mathrm{~cm}^{-1}$ was much higher in $\mathrm{A}$ and $\mathrm{B}$, indicating that the uronic acid in $C$ was much lower than $A$ and $B$. The absorption at $1225-1240 \mathrm{~cm}^{-1}(S=O$ stretching vibration) confirmed the presence of sulfates in $A$ and $C$. The band at $1239 \mathrm{~cm}^{-1}$ in $C$ was much higher than that in $A$, indicating that the sulfate group was much higher than $C$. No band at $1225-1240 \mathrm{~cm}^{-1}$ was found in B, indicating that there was little sulfate group in B [19]. The band at 
$816 \mathrm{~cm}^{-1}$ suggested A and B were mainly sulfated at C-2 and/or C-3 on fucose or C-2 on galactose residues. However, the band of $C-O-S$ vibration of $C$ shifted to $844.6 \mathrm{~cm}^{-1}$, indicating the sulfation at C-4 on fucose residues [20].

\subsection{Antioxidant Activity of A. nodosum Polysaccharides}

As shown in Figure 4A, all the samples showed increased scavenging activity in a concentrationdependent manner. At the polysaccharide concentration of $4 \mathrm{mg} / \mathrm{mL}$, the AnPS, AnP1-1 and AnP2-1 extracts scavenged $70.5 \%, 45.2 \%$ and $69.5 \%$, respectively, of the ABTS radical, while the positive control Vc scavenged 100\%. This shown that the AnPS and its purified fractions had strong ABTS scavenging activity. AnP2-1 displayed superior ABTS radical scavenging activity, which might be due to the higher Fuc content (Table 3) [21].

The scavenging effects on DPPH free radicals were presented in Figure $4 \mathrm{~B}$. The scavenging activity of the polysaccharides increased with an increase in their concentration. At a concentration of $4 \mathrm{mg} / \mathrm{mL}$, the DPPH free radical scavenging activities of crude AnPS, AnP1-1, AnP2-1 and Vc were $45.9 \%, 30.4 \%, 32.5 \%$ and $98.2 \%$, respectively. Compared with the results of the ABTS assay, the AnPS and its purified fractions had limited scavenging abilities for DPPH. The reason might be due to the facts that the ABTS assay is more suitable for evaluating hydrophilic antioxidants [22].
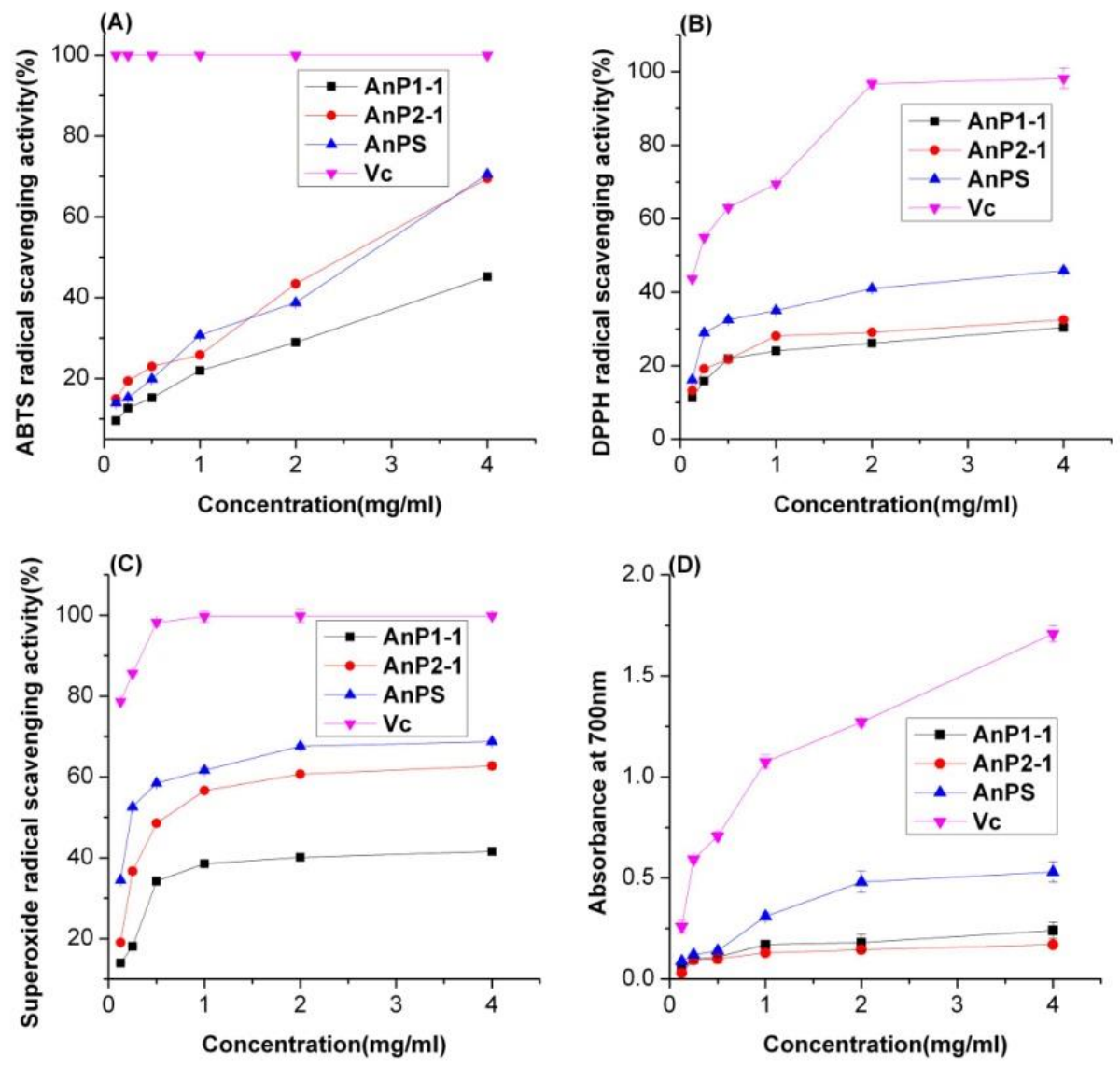

Figure 4. Scavenging abilities of A. nodosum polysaccharides from crude extract (AnPS) and two purified fractions (AnP1-1 and AnP2-1) on ABTS radical (A), DPPH radical (B) and superoxide radical (C) and their reducing power (D).

The superoxide radical scavenging activity of AnPS and its purified fractions were measured by the PMS/NADH-NBT system (Figure 4C). For all samples, the superoxide anion radical scavenging activities increased with increasing sample concentrations, which was similar to those of the ABTS and 
DPPH assays. At the concentration of $4.0 \mathrm{mg} / \mathrm{mL}$, the superoxide anion radical scavenging activities of AnPS, AnP1-1, AnP2-1 and Vc were 68.8\%, 41.6\%, 62.7\% and 99.8\%, respectively. The AnPS and AnP2-1 showed stronger scavenging activity than AnP1-1. This may partly be related to the higher sulfate group content in AnPS and AnP2-1 [23]. As shown in Figure 4D, the reducing power of the AnPS and its purified fractions increased with increasing concentration. Compared with $\mathrm{V}_{\mathrm{c}}$, the AnPS, AnP1-1 and AnP2-1 fractions exhibited significantly lower reducing power. At a concentration of $4.0 \mathrm{mg} / \mathrm{mL}$, the reducing power was 0.53, 0.24, 0.17 and 1.71 for AnPS, AnP1-1, AnP2-1 and Vc, respectively, and the reducing power was 30\%,12\% and $10 \%$ of Vc. The AnPS showed stronger reducing power than the AnP1-1 and AnP2-1, which might partly be due to the ratio of sulfate/fucose [24].

\subsection{Protective Effect on $\mathrm{H}_{2} \mathrm{O}_{2}$-Induced Oxidative Injury}

$\mathrm{H}_{2} \mathrm{O}_{2}$ was considered as a by-product of dopamine oxidation and enzymatic action, which may lead to neuronal damage and oxidative stress through release of reactive oxygen species (ROS) [24]. Furthermore, large numbers of reports shows that oxidative injury is related to a wide range of disease, including diabetes mellitus, arteriosclerosis, Alzheimer's disease, nephritis and even cancer, due to the excessive production of ROS [10]. In this work, the protective effect of AnP1-1 and AnP2-1 on $\mathrm{H}_{2} \mathrm{O}_{2}$-induced oxidative injury was carried out to verify the antioxidant in cellular level. As showed in Figure 5, $\mathrm{H}_{2} \mathrm{O}_{2}$ solution treatment significantly induced oxidative injury in RAW264.7 cells, and the cell viability decreased from $100.0 \pm 5.7 \%$ to $55.8 \pm 6.7 \%$, suggested that the model was reliable. As expected, the pre-incubation with AnP1-1 and AnP2-1 could significantly increase the cell viability in a dose-dependent manner, indicated that AnP1-1 and AnP2-1 could attenuate the $\mathrm{H}_{2} \mathrm{O}_{2}$-induced oxidative injury in RAW264.7 cells. Notably, AnP2-1 showed higher protective effect on RAW264.7 cells than AnP1-1, which might be due to the higher content of sulfate group in AnP2-1. Likewise, Di et al. also found that polysaccharides from Gracilaria rubra with higher content of sulfate groups had stronger antioxidant activities [25].

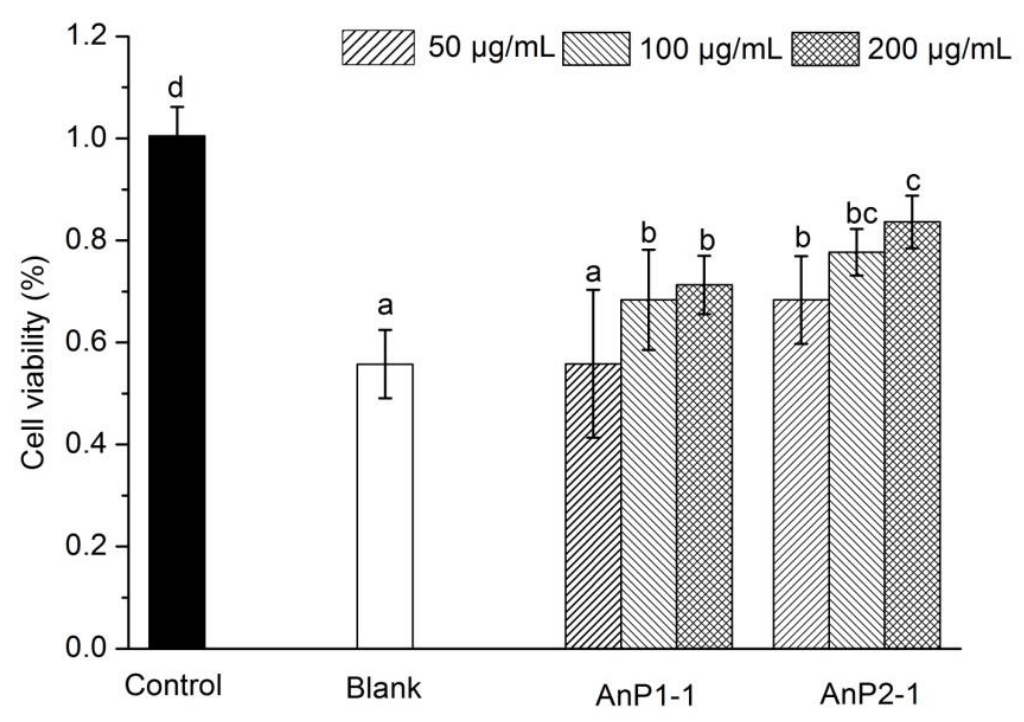

Figure 5. The protective effect of AnP1-1 and AnP2-1 against $\mathrm{H}_{2} \mathrm{O}_{2}$-induced oxidative injury in RAW264.7 cells. The different letters represent significant differences between different groups $(p<0.05)$.

\subsection{Immunostimulatory Activity on Caco-2 Cells}

The cytokines, which are small molecule proteins produced by immune cells, could reflect the abilities of immunomodulatory and anti-inflammatory [26]. In the present study, the effects of AnP1-1 and AnP2-1 under different concentrations (0, 25, 50, 100 and $200 \mu \mathrm{g} / \mathrm{mL})$ on the production of cytokines, including IFN- $\gamma, \mathrm{TNF}-\alpha, \mathrm{IL}-1 \beta$, and IL- 8 , were investigated in the Caco- 2 
cell model. The results showed that both AnP1-1 and AnP2-1 had limited effect on the levels of IFN- $\gamma$ (Figure 6A). As expected, the minimum levels of TNF- $\alpha$, IL- 8 , and IL-1 $\beta$ were observed in untreated Caco- 2 cells, where as the productions of TNF- $\alpha$, IL- 8 , and IL- $1 \beta$ were significantly enhanced after the treatment of AnP1-1. The AnP2-1 treatment could also facilitate the release of TNF- $\alpha$, IL-8, and IL-1 $\beta$ in a dose-dependent manner, which showed much better than that of AnP1-1. It has been reported that a heteropolysaccharide L2 from Lentinula edodes could also enhance the production of anti-inflammatory cytokine IL-10 and proinflammatory cytokines (IFN- $\gamma$, TNF- $\alpha$, IL-8 and IL-12) in Caco-2 cells [27]. The results indicated that both AnP1-1 and AnP2-1 could stimulate immune responses of Caco-2 cells through the release of immune cell factors. Recently, there is growing number of work has demonstrated that sulfated polysaccharides, especially from brown and green seaweeds, had superior immunomodulatory activities, which was related to the high contents of sulfate groups [25]. In the present study, the contents of sulfate groups in AnP1-1 and AnP2-1 were $5.4 \pm 0.11$ and $23.8 \pm 0.02$, respectively, which may result in a much stronger immunostimulatory activity of AnP2-1. Unfortunately, the potential molecular mechanism of immunostimulatory activity of AnP1-1 and AnP2-1 is still unknown, it will be our next work.
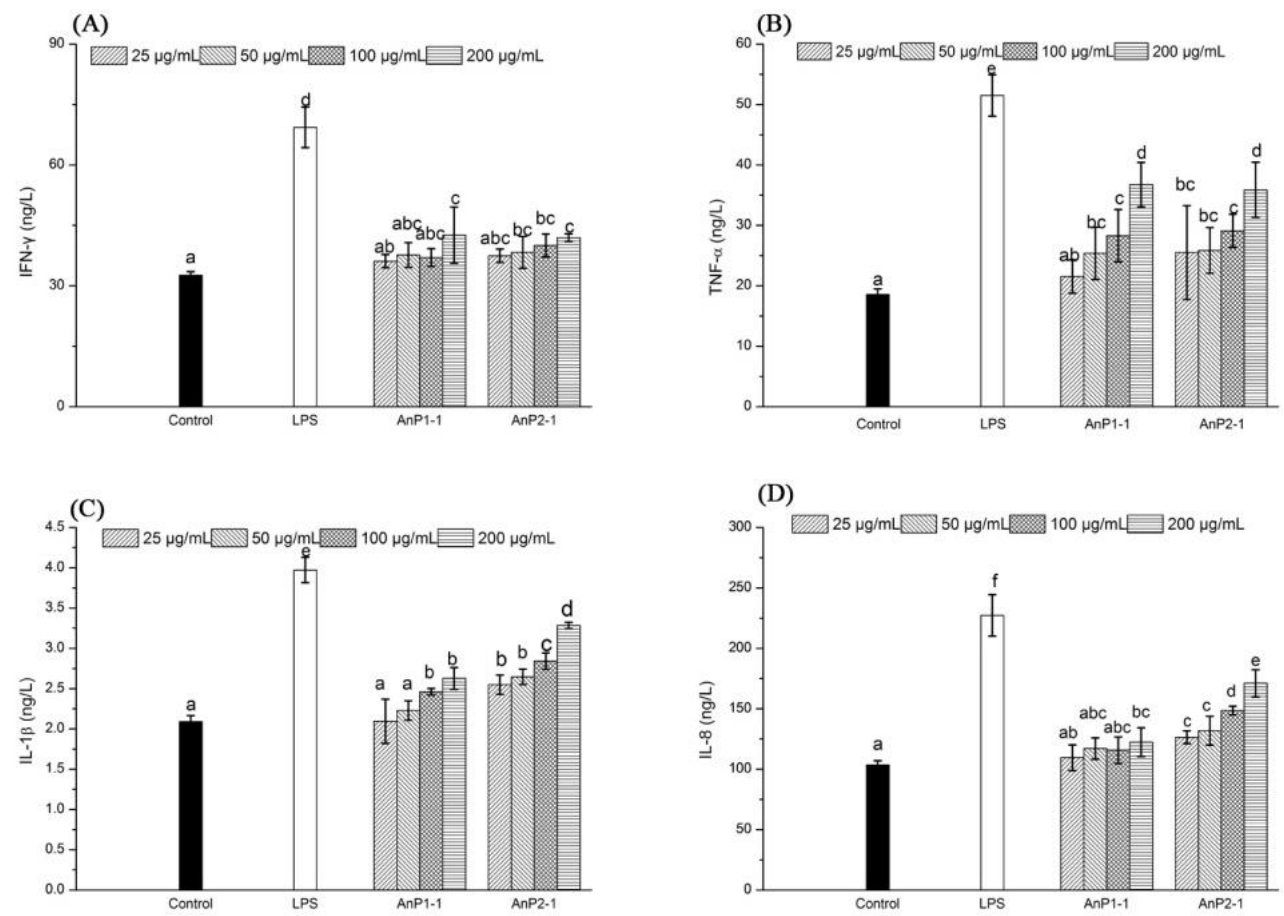

Figure 6. Effects of AnP1-1 and AnP2-1 on Cytokine IFN- $\gamma$ (A), TNF- $\alpha$ (B), I L-1 $\beta$ (C) and IL-8 (D) Levels of Caco-2 Cells. The different letters represent significant differences between different groups $(p<0.05)$.

\section{Materials and Methods}

\subsection{Materials and Chemicals}

The sample of Ascophyllum nodosum was obtained from Mingyue Seaweed Corporation (Qindao, Shangdong, China). DEAE Sepharose Fast Flow and Sephacryl S-300 were purchased from GE (Uppsala, Sweden). 1-phenyl-3-methyl-5-pyrazolone (PMP), D-series dextran standards and standard monosaccharides were purchased from Sigma-Aldrich Co., Ltd. (St. Louis, MO, USA). Nitrotetrazolium blue chloride (NBT), phenazine methosulfate (PMS), 2,2'-azinobis-(3-ethylbenzoth-iazoline-6-sulfonic acid) (ABTS) and 2,2-diphenyl-1-picrylhydrazyl (DPPH) were purchased from Aladdin Chemical Reagent Co., Ltd. (Shanghai, China). Mulbecco's modified Eagle medium (DMEM), fetal calf serum, 
trypsin-EDTA, streptomycin and penicillin were purchased from Gibco/Invitrogen (Carlsbad, CA, USA). The 3-(4,5-dimethylthiazol-2-yl)-2,5-diphenyltetrazolium bromide (MTT) and lipopolysaccharides (LPS) were obtained from Sigma Chemical Co. The RAW264.7 cells and Caco-2 cells were purchased from Keygen Co. (Nanjing, China). Enzyme-linked immunosorbent assay (ELISA) kits for IFN- $\gamma$, IL-8, TNF- $\alpha$ and I L-1 $\beta$ were purchased from Nanjing Jiancheng Bioengineering Institute (Nanjing, China). All other reagents and solvents were of analytical grade.

\subsection{Extraction of Crude AnPS}

The polysaccharides were extracted according to the previous method [28]. The dried Ascophyllum nodosum powder was extracted with $80 \%$ ethanol three times for $36 \mathrm{~h}$ in order to remove the small molecules, and then was extracted using hot water under the conditions determined by response surface methodology (RSM) of the designed extraction temperature, extraction time and ratio of water to raw material. The extract was combined, centrifuged and concentrated. The solution was deproteinated using the Sevag method [28], dialyzed and lyophilized to obtain the crude Ascophyllum nodosum polysaccharides (AnPS). The extraction yield was calculated according to the following formula:

$$
\text { Extraction yield }(\%)=\mathrm{W}_{1} / \mathrm{W} \times 100
$$

where $W_{1}$ and $W$ are the weights of AnPS and the dried powder sample, respectively.

\subsection{Design of Experimental (DoE) in Response Surface Methodology (RSM)}

According to single-factor tests, a BBD with three independent variables $\left(\mathrm{X}_{1}\right.$, extraction temperature; $X_{2}$, extraction time; $X_{3}$, ratio of water to raw material) at three levels was performed. The whole design consisted of 17 computed experimental runs (12 factorial point and 5 axial points). All the design points were modeled in triplicate in a randomized order. The experimental data (Table 1) were analyzed by multiple regressions to fit the following second-order polynomial mode [16]:

$$
\mathrm{Y}=\beta_{0}+\sum_{i=1}^{3} \beta_{i} \mathrm{X}_{i}+\sum_{i=1}^{3} \beta_{i i} \mathrm{X}_{i}^{2}+\sum_{i=1}^{2} \sum_{j=i+1}^{3} \beta_{i i} \mathrm{X}_{i} \mathrm{X}_{j}
$$

where $\mathrm{Y}$ is the predicted response (extraction yield of AnPS); $\beta_{0}, \beta_{i}, \beta_{i i}$ and $\beta_{i j}$ are the regression coefficients for intercept, linear, quadratic and interaction terms, respectively; $X_{i}$ and $X_{j}$ are the independent variables $(i \neq j)[15]$.

\subsection{Purification of A. nodosum Polysaccharides (AnPS)}

Crude AnPS was dissolved in deionized water $(20 \mathrm{~mL}, 15 \mathrm{mg} / \mathrm{mL})$ and loaded into a DEAE Sepharose Fast Flow chromatography column $(2.6 \mathrm{~cm}$ i.d. $\times 60 \mathrm{~cm})$, the column was stepwise eluted by $0,0.5$ and $1.0 \mathrm{M}$ sodium chloride $(\mathrm{NaCl})$ solution at a flow rate of $2.5 \mathrm{~mL} / \mathrm{min}$ and the eluent was collected $10 \mathrm{~mL}$ per tube. Two completely separated fractions, AnP1 and AnP2, were collected by checking the absorbance at $490 \mathrm{~nm}$ by using phenol-sulfuric acid method [9]. Then, the polysaccharide fractions were dialyzed and purified further by Sephacryl S-300 size-exclusiong chromatography column $(1.6 \mathrm{~cm}$ i.d. $\times 100 \mathrm{~cm})$. The column was eluted with $0.1 \mathrm{M}$ aqueous $\mathrm{NaCl}$ solution at a rate of $40 \mathrm{~mL} / \mathrm{h}$. As a result, the main fractions were collected, dialyzed and lyophilized, respectively, affording AnP1-1 and AnP2-1.

\subsection{Analysis and Characterization of the Polysaccharide Fractions}

The contents of carbohydrate in AnPS, AnP1-1 and AnP2-1 were measured by the phenol-sulphuric acid method [29]. The content of protein was determined according to the method of Bradford [30]. The content of total polyphenols was estimated by the Folin-Ciocalteu colori-metric method [31]. The content of uronic acid was estimated according to the method of Blumenkrantz and 
Asboe-Hansen [32]. The content of sulfate group was determined according to the reported method of Doigson and Price [33].

The homogeneity and molecular weight of AnP1-1 and AnP2-1 were determined using high performance gel permeation chromatography (HPGPC, Waters Technologies) equipped with a TSK-G $3000 \mathrm{PWxL}$ column. The column temperature was set at $30^{\circ} \mathrm{C}$. The column was eluted with double distilled water at a rate of $0.7 \mathrm{~mL} / \mathrm{min}$. The D-series dextran standards (D-2, D-3, D-4, D-5, D-6, D-7 and D-8) were employed to obtain the calibration curve. The sample concentration was set at $2.0 \mathrm{mg} / \mathrm{mL}$.

The monosaccharide composition of AnP1-1 and AnP2-1 were analyzed by HPLC using reported methods [33]. The sample (5 mg) was hydrolyzed with trifluoroacetic acid (TFA, $2 \mathrm{M}$ ) for $2 \mathrm{~h}$ at $120^{\circ} \mathrm{C}$. The resultant solution was cooled to the room temperature and was evaporated to dryness under reduced pressure repeatedly. The residue was dissolved in methanol $(200 \mu \mathrm{L})$ and evaporated again to dryness. The residue was derived by PMP, according to the reported method [28]. The products were analyzed on a HPLC system (Agilent 1200) equipped with Eclipse Plus C18 column $(4.6 \times 250 \mathrm{~mm}$, $5 \mu \mathrm{m}$, Agilent) and photodiode array detector. The chromatographic conditions were as follows: detector wavelength, $245 \mathrm{~nm}$; column temperature, $30^{\circ} \mathrm{C}$; flow rate, $1.0 \mathrm{~mL} / \mathrm{min}$; mobile phase, a mixture of acetonitrile and phosphate buffered saline (PBS, 0.1 M, pH 6.7) in a ratio of 83:17 (v/v).

Dried polysaccharide samples (crude AnPS, AnP1-1 and AnP2-1) were mixed with $\mathrm{KBr}$ powder and the mixture was pressed into a pellet. The samles were characterized by FT-IR on a spectrophotometer (Nexus 6700, Bruker Co., Karlsruhe, Germany) in the range of $400-4000 \mathrm{~cm}^{-1}$.

\subsection{Antioxidant Activity Assays}

\subsubsection{ABTS Assay}

The crude AnPS and the purified fractions AnP1-1 and AnP2-1 were subjected to an ABTS assay $[15,34]$ with some modifications. The ABTS radical solution was generated through the reaction of potassium persulfate $(3.8 \mathrm{mM})$ and ABTS $(7.4 \mathrm{mM})$ for $16 \mathrm{~h}$ at $25^{\circ} \mathrm{C}$ in the dark. The solution was diluted with PBS buffer ( $\mathrm{pH} 7.4$ ) to obtain an absorbance of $0.70 \pm 0.01$ at $734 \mathrm{~nm}$. Ascorbic acid (vitamin C, Vc) was used as a positive standard. Sample solutions (Vc, AnPS, AnP1-1 and AnP2-1) were diluted to $0.125,0.25,0.5,1.0,2.0$ and $4.0 \mathrm{mg} / \mathrm{mL}$. The diluted samples $(25 \mu \mathrm{L})$ were mixed with $250 \mu \mathrm{L}$ ABTS solution. After mixing for $6 \mathrm{~min}$ at room temperature, the absorbance of the mixture was measured at $734 \mathrm{~nm}$. The ABTS radical scavenging activity was calculated by the following formula:

$$
\text { ABTS radical scavenging activity }(\%)=\left[1-\left(\mathrm{A}_{1}-\mathrm{A}_{2}\right) / \mathrm{A}_{0}\right] \times 100
$$

where $A_{1}$ is the absorbance of the sample solution, $A_{2}$ is the absorbance of the solution containing sample and PBS, and $\mathrm{A}_{0}$ is the absorbance of the solution containing ABTS and distilled water.

\subsubsection{DPPH Radical Scavenging Activity}

DPPH radical scavenging activity was determined using the reported method [35]. Briefly, $50 \mu \mathrm{L}$ sample solution of different concentrations $(0.125,0.25,0.5,1.0$ and $2.0 \mathrm{mg} / \mathrm{mL})$ was added to $50 \mu \mathrm{L}(0.2 \mathrm{mM})$ DPPH-methanol solution in a 96-well plate. After vigorous shaking, the reaction was kept in the dark at room temperature for $30 \mathrm{~min}$. The absorbance was measured at $517 \mathrm{~nm}$ with $\mathrm{Vc}_{\mathrm{c}}$ as a positive standard. The scavenging activity of DPPH radical was calculated by the following formula:

$$
\text { DPPH radical scavenging activity }(\%)=\left[1-\left(\mathrm{A}_{1}-\mathrm{A}_{2}\right) / \mathrm{A}_{0}\right] \times 100
$$

where $A_{1}$ is the absorbance of the reaction solution, $A_{2}$ is the absorbance of the solution containing sample and ethanol, and $\mathrm{A}_{0}$ is the absorbance of the solution containing DPPH and distilled water. 


\subsubsection{Superoxide Anion Radical Scavenging Activity}

The superoxide anion radical scavenging activity was measured according to the reported method [36] with minor modifications. In this experiment, $50 \mu \mathrm{L}$ NADH solution $(78 \mu \mathrm{M}), 50 \mu \mathrm{L}$ PMS solution $(10 \mu \mathrm{M}), 50 \mu \mathrm{L}$ NBT solution $(78 \mu \mathrm{M})$ and $50 \mu \mathrm{L}$ sample solution $(0.125,0.25,0.5,1.0,2.0$ and $4.0 \mathrm{mg} / \mathrm{mL}$ ) were mixed in a 96-well plate. The reaction solution was incubated at $25^{\circ} \mathrm{C}$ for $5 \mathrm{~min}$. The absorbance of the reaction was measured at $560 \mathrm{~nm}$ with $\mathrm{V}_{\mathrm{C}}$ as positive control. The superoxide anion radical scavenging activity was calculated using the following formula:

$$
\text { Superoxide anion radical scavenging activity }(\%)=\left[1-\left(\mathrm{A}_{1}-\mathrm{A}_{2}\right) / \mathrm{A}_{0}\right] \times 100
$$

where $A_{1}$ is the absorbance of the sample solution, $A_{2}$ is the absorbance of the sample only (PBS buffer), and $\mathrm{A}_{0}$ is the absorbance of the control (distilled water).

\subsubsection{Reducing Power Assay}

The reducing power of AnPS was quantified by the reported method with some modifications [37]. Briefly, $50 \mu \mathrm{L}$ PBS ( $\mathrm{pH} 6.6,0.2 \mathrm{M}), 50 \mu \mathrm{L}$ potassium ferricyanide $(1 \%, w / v)$ and $50 \mu \mathrm{L}$ sample solutions $(0.125,0.25,0.5,1.0,2.0$ and $4.0 \mathrm{mg} / \mathrm{mL})$ were mixed and incubated at $50{ }^{\circ} \mathrm{C}$ for $20 \mathrm{~min}$ in a 96 -well plate. After cooling rapidly, $50 \mu \mathrm{L}$ TCA solution $(10 \%, w / v)$ was added to the mixture and centrifuged at $8000 \mathrm{rpm}$ for $10 \mathrm{~min}$. The supernatant solution was transferred and mixed with $25 \mu \mathrm{L}$ ferric chloride $(0.1 \%, w / v)$ and $25 \mu \mathrm{L}$ of distilled water. The absorbance of the reaction mixture was recorded at $700 \mathrm{~nm}$ with $\mathrm{Vc}$ as positive control. The reducing power was calculated according to the formula:

$$
\text { Reducing power }=\mathrm{A}_{1}-\mathrm{A}_{2}
$$

where $A_{1}$ is the absorbance of reaction mixture of sample, $A_{2}$ is the absorbance of sample solution without ferric chloride.

\subsection{Protective Effect on $\mathrm{H}_{2} \mathrm{O}_{2}$-Induced Oxidative Injury}

The protective effect of AnPS, AnP1-1 and AnP2-1 on $\mathrm{H}_{2} \mathrm{O}_{2}$-induced oxidative injury on RAW264.7 was carried out according to the previous method with some modification by MTT assay [25]. The RAW264.7 cells were cultured in DMEM supplemented with fetal calf serum (10\%, $v / v)$ and penicillin-streptomycin $(1 \%, v / v)$ in a humidified atmosphere containing $\mathrm{CO}_{2}(5 \%)$ at $37^{\circ} \mathrm{C}$. $200 \mu \mathrm{L} /$ well of RAW264.7 cells suspension was pipetted into a 96-well culture plate and incubated for $12 \mathrm{~h}$. The culture medium was replaced by new culture medium with different concentrations $(0,50,100$ and $200 \mu \mathrm{g} / \mathrm{mL}$ ) of samples (AnP1-1 and AnP2-1). After culture of $24 \mathrm{~h}$, the culture medium with $850 \mu \mathrm{M}$ of $\mathrm{H}_{2} \mathrm{O}_{2}$ was added after removal of the old culture medium and incubated for a further $2 \mathrm{~h}$. Then, the medium was removed, $50 \mu \mathrm{L}$ of MTT solution $(2 \mathrm{mg} / \mathrm{mL})$ was added and incubated for $4 \mathrm{~h}$ at $37^{\circ} \mathrm{C}$. Finally, $150 \mu \mathrm{L}$ of DMSO was added into each well to replace MTT solution. The absorbance at $570 \mathrm{~nm}$ was measured with a microplate reader. The cell viability was calculated by the following equation:

$$
\text { Cell viability }=\mathrm{As} / \mathrm{A}_{0}
$$

where As is the absorbance of the sample and $\mathrm{A}_{0}$ is the absorbance of blank.

\subsection{Assay of Immunostimulatory Activity In Vitro}

The assay of immunostimulatory activity in vitro was carried out using Caco-2 cells model according to the previous method [26]. $200 \mu \mathrm{L} /$ well of Caco-2 cells suspension was pipetted into a 96-well culture plate and incubated for $12 \mathrm{~h}$. The culture medium was replaced by new culture medium with different concentrations $(0,25,50,100$ and $200 \mu \mathrm{g} / \mathrm{mL}$ ) of samples (AnP1-1 and AnP2-1) or LPS $(1 \mu \mathrm{g} / \mathrm{mL})$. After culture of $24 \mathrm{~h}$, the levels of IFN- $\gamma, \mathrm{TNF}-\alpha, \mathrm{IL}-1 \beta$, and IL-8 in 
the supernatants of the Caco-2 cells from each group were evaluated by using ELISA kits according to the manufacturers' protocols (Nanjing Jiancheng Bioengineering Institute, Nanjing, China). LPS was used as positive control.

\subsection{Statistical Analysis}

All measurements were performed in triplicate and the average values were reported. Analysis of variance (ANOVA) followed by Duncan's multiple-range tests with $P<0.05$ were used to determine significant differences.

\section{Conclusions}

In this work, the optimized conditions for extraction of sulfated polysaccharide from Ascophyllum nodosum were determined as follows: extraction temperature of $84^{\circ} \mathrm{C}$, extraction time of $4.3 \mathrm{~h}$ and a ratio of water to raw material of $27 \mathrm{~mL} / \mathrm{g}$. Under these predicted conditions the polysaccharide yield was $9.2 \pm 0.23 \%$. Two fractions, AnP1-1 and AnP2-1, with molecular weights of 165.92 KDa and $370.68 \mathrm{KDa}$, respectively, were obtained by using chromatography with DEAE Sepharose Fast Flow and Sephacryl S-300. The monosaccharide composition of AnPS was composed of mannose, glucuronic acid, glucose, galactose, xylose and fucose, AnP1-1 was composed of mannose, ribose, glucuronic acid, glucose and fucose and AnP2-1 was composed of mannose, glucuronic acid, galactose and fucose. Crude AnPS, AnP1-1 and AnP2-1 exhibited high scavenging activities against ABTS and superoxide radicals, and protective effect on $\mathrm{H}_{2} \mathrm{O}_{2}$-induced oxidative injury in RAW264.7 cells. Furthermore, both AnP1-1 and AnP2-1 had stronger intestinal immunostimulatory activities evaluated by Caco- 2 model. These results indicated that AnPS and its purified fractions could be used as potential antioxidants and intestinal immune stimulators. Further study is required to give more insight into the relationship between the mechanisms behind these biologically important activities and the structure of AnPS and its purified fractions.

Author Contributions: L.C., W.X. and H.Z. conceived and designed the experiments; Y.W., H.L. and H.Y. performed the experiments; L.C. and G.C. analyzed the data; L.C. wrote the paper.

Funding: This work is financially supported provided by the Natural Science Foundation of the Jiangsu Higher Education Institutions of China (Grant No. 17KJA530006) and the open project of Jiangsu Key Laboratory of Biochemistry and Biotechnology of Marine Wetland at Yancheng Institute of Technology (K2016-07).

Acknowledgments: The authors are grateful for financial supported provided by the Natural Science Foundation of the Jiangsu Higher Education Institutions of China (Grant No. 17KJA530006) and the open project of Jiangsu Key Laboratory of Biochemistry and Biotechnology of Marine Wetland at Yancheng Institute of Technology (K2016-07).

Conflicts of Interest: The authors declare that there is no conflict of interest regarding the publication of this paper.

\section{References}

1. Chan, C.X.; Ho, C.L.; Phang, S.M. Trends in seaweed research. Trends Plant Sci. 2006, 11, 165-166. [CrossRef] [PubMed]

2. Alamoudi, O.A.; Mutawie, H.H.; Patel, A.V.; Blunden, G. Chemical composition and antioxidant activities of Jeddah corniche algae, Saudi Arabia. Saudi J. Biol. Sci. 2009, 16, 23-29. [CrossRef] [PubMed]

3. Yuan, Y.; Macquarrie, D.C. Microwave assisted extraction of sulfated polysaccharides (fucoidan) from Ascophyllum nodosum and its antioxidant activity. Carbohydr. Polym. 2015, 129, 101-107. [CrossRef] [PubMed]

4. Kindleysides, S.; Quek, S.Y.; Miller, M.R. Inhibition of fish oil oxidation and the radical scavenging activity of New Zealand seaweed extracts. Food Chem. 2012, 133, 1624-1631. [CrossRef]

5. Balboa, E.M.; Conde, E.; Moure, A.; Falqué, E.; Domínguez, H. In vitro antioxidant properties of crude extracts and compounds from brown algae. Food Chem. 2013, 138, 1764-1785. [CrossRef] [PubMed]

6. Zhang, Z.S.; Wang, F.; Wang, X.M.; Liu, X.L.; Hou, Y.; Zhang, Q.B. Extraction of the polysaccharides from five algae and their potential antioxidant activity in vitro. Carbohydr. Polym. 2010, 82, 118-121. [CrossRef] 
7. Yang, W.N.; Chen, P.W.; Huang, C.Y. Compositional characteristics and in vitro evaluations of antioxidant and neuroprotective properties of crude extracts of fucoidan prepared from compressional puffing-pretreated Sargassum crassifolium. Mar. Drugs 2017, 15, 183. [CrossRef] [PubMed]

8. Yu, P.; Sun, H. Purification of a fucoidan from kelp polysaccharide and its inhibitory kinetics for tyrosinase. Carbohydr. Polym. 2014, 99, 278-283. [CrossRef] [PubMed]

9. Han, Y.; Wu, J.; Liu, T.T.; Hu, Y.D.; Zheng, Q.S.; Wang, B.S.; Lin, H.Y.; Li, X. Separation, characterization and anticancer activities of a sulfated polysaccharide from Undaria pinnatifida. Int. J. Biol. Macromol. 2016, 83, 42-49. [CrossRef] [PubMed]

10. Chen, G.J.; Yuan, Q.X.; Saeeduddin, M.; Ou, S.; Zeng, X.X.; Ye, H. Recent advances in tea polysaccharides: Extraction, purification, physicochemical characterization and bioactivities. Carbohydr. Polym. 2016, 153, 663-678. [CrossRef] [PubMed]

11. Chen, G.J.; Xie, M.H.; Wan, P.; Chen, D.; Ye, H.; Chen, L.G.; Zeng, X.X.; Liu, Z.H. Digestion under saliva, simulated gastric and small intestinal conditions and fermentation in vitro by human intestinal microbiota of polysaccharides from Fuzhuan brick tea. Food Chem. 2018, 244, 331-339. [CrossRef] [PubMed]

12. Yu, Z.D.; Song, G.; Liu, J.; Wang, J.Y.; Zhang, P.Y.; Chen, K.S. Beneficial effects of extracellular polysaccharide from Rhizopus nigricans on the intestinal immunity of colorectal cancer mice. Int. J. Biol. Macromol. 2018, 115, 718-726. [CrossRef] [PubMed]

13. Kim, H.; Yu, K.W.; Hong, H.D.; Shin, K.S. Effect of arabinoxylan- and rhamnogalacturonan I-rich polysaccharides isolated from young barley leaf on intestinal immunostimulatory activity. Funct. Foods 2017, 35, 384-390. [CrossRef]

14. Brito, T.V.; Barros, F.C.N.; Silva, R.O.; Dias Júnior, G.J.; Júnior, J.S.C.; Franco, Á.X.; Soares, P.M.G.; Chaves, L.S.; Abreu, C.M.W.S.; de Paula, R.C.M.; et al. Sulfated polysaccharide from the marine algae Hypnea musciformis inhibits TNBS-induced intestinal damage in rats. Carbohydr. Polym. 2016, 151, 957-964. [CrossRef] [PubMed]

15. Hammi, K.M.; Hammami, M.; Rihouey, C.; Cerf, D.L.; Ksouri, R.; Majdoub, H. Optimization extraction of polysaccharide from Tunisian Zizyphus lotus fruit by response surface methodology: Composition and antioxidant activity. Food Chem. 2016, 212, 476-484. [CrossRef] [PubMed]

16. Samavati, V.; Yarmand, M.S. Statistical modeling of process parameters for the recovery of polysaccharide from Morus alba leaf. Carbohydr. Polym. 2013, 98, 793-806. [CrossRef] [PubMed]

17. Ren, B.B.; Chen, C.; Li, C.; Fu, X.; You, L.J.; Liu, R.H. Optimization of microwave-assisted extraction of Sargassum thunbergii polysaccharides and its antioxidant and hypoglycemic activities. Carbohydr. Polym. 2017, 173, 192-201. [CrossRef] [PubMed]

18. Cao, C.L.; Huang, Q.; Zhang, B.; Li, C.; Fu, X. Physicochemical characterization and in vitro hypoglycemic activities of polysaccharides from Sargassum pallidum by microwave-assisted aqueous two-phase extraction. Int. J. Biol. Macromol. 2018, 109, 357-368. [CrossRef] [PubMed]

19. Thambiraj, S.R.; Phillips, M.; Koyyalamudi, S.R.; Reddy, N. Antioxidant activities and characterisation of polysaccharides isolated from the seeds of Lupinus angustifolius. Ind. Crop. Prod. 2015, 74, 950-956. [CrossRef]

20. Souza, B.W.; Cerqueira, M.A.; Bourbon, A.I.; Pinheiro, A.C.; Martins, J.T.; Teixeira, J.A.; Coimbra, M.A.; Vicente, A.A. Chemical characterization and antioxidant activity of sulfated polysaccharide from the red seaweed Gracilaria birdiae. Food Hydrocol. 2012, 27, 287-292. [CrossRef]

21. Floegel, A.; Kim, D.O.; Chung, S.J.; Koo, S.I.; Chun, O.K. Comparison of ABTS/DPPH assays to measure antioxidant capacity in popular antioxidant-rich US foods. J. Food Compd. Anal. 2011, 24, 1043-1048. [CrossRef]

22. Wang, J.; Zhang, Q.B.; Zhang, Z.S.; Li, Z.E. Antioxidant activity of sulfated polysaccharide fractions extracted from Laminaria japonica. Int. J. Biol. Macromol. 2008, 42, 127-132. [CrossRef] [PubMed]

23. Wang, J.Q.; Zhang, B.; Zhang, Z.S.; Song, H.F.; Li, P.C. Potential antioxidant and anticoagulant capacity of low molecular weight fucoidan fractions extracted from Laminaria japonica. Int. J. Biol. Macromol. 2010, 46, 6-12. [CrossRef] [PubMed]

24. Qin, Y.J.; Yuan, Q.X.; Zhang, Y.X.; Li, J.L.; Zhu, X.J.; Zhao, L.L.; Wen, J.; Liu, J.K.; Zhao, L.Y.; Zhao, J.H. Enzyme-Assisted Extraction Optimization, Characterization and Antioxidant Activity of Polysaccharides from Sea Cucumber Phyllophorus proteus. Molecules 2018, 23, 590. [CrossRef] [PubMed]

25. Di, T.; Chen, G.J.; Sun, Y.; Ou, S.; Zeng, X.X.; Ye, H. Antioxidant and immunostimulating activities in vitro of sulfated polysaccharides isolated from Gracilaria rubra. J. Funct. Foods 2017, 28, 64-75. [CrossRef] 
26. Shim, W.B.; Kim, K.Y.; Chung, D.H. Development and Validation of a Gold Nanoparticle Immunochromatographic Assay (ICG) for the Detection of Zearalenone. J. Agric. Food Chem. 2009, 57, 4035-4041. [CrossRef] [PubMed]

27. Xu, X.F.; Yang, J.G.; Luo, Z.; Zhang, X.W. Lentinula edodes-derived polysaccharide enhances systemic and mucosal immunity by spatial modulation of intestinal gene expression in mice. Food Funct. 2015, 6, 2068-2080. [CrossRef] [PubMed]

28. Yuan, Q.X.; Xie, Y.F.; Wang, W.; Yan, Y.H.; Ye, H.; Jabbar, S.; Zeng, X.X. Extraction optimization, characterization and antioxidant activity in vitro of polysaccharides from mulberry (Morus alba L.) leaves. Carbohydr. Polym. 2015, 128, 52-62. [CrossRef] [PubMed]

29. Dubois, M.; Gilles, K.A.; Hamilton, J.K.; Rebers, P.A.; Smith, F. Colorimetric method for determination of sugars and related substances. Anal. Chem. 1956, 28, 350-356. [CrossRef]

30. Bradford, M.M. A rapid and sensitive method for the quantitation of microgram quantities of protein utilizing the principle of protein-dye binding. Anal. Biochem. 1976, 72, 248-254. [CrossRef]

31. Li, J.E.; Nie, S.P.; Xie, M.Y.; Li, C. Isolation and partial characterizationof a neutral polysaccharide from Mosla chinensis Maxim. cv. Jiangxiangru and its antioxidant and immunomodulatory activities. J. Funct. Foods 2014, 6, 410-418. [CrossRef]

32. Blumenkrantz, N.; Asboe-Hansen, G. New method for quantitative determination of uronic acids. Anal. Biochem. 1973, 54, 484-489. [CrossRef]

33. Doigson, K.S.; Price, R.G. A note on the determination of the ester sulfate content of sulfated polysaccharides. Biochem. J. 1962, 84, 106-110. [CrossRef]

34. Xie, M.H.; Hu, B.; Wang, Y.; Zeng, X.X. Grafting of gallic acid onto chitosan enhances antioxidant activities and alters rheological properties of the copolymer. J. Agric. Food Chem. 2014, 62, 9128-9136. [CrossRef] [PubMed]

35. Xiao, J.B.; Huo, J.L.; Jiang, H.X.; Yang, F. Chemical compositions and bioactivites of crude polysaccharides from tea leaves beyond their useful date. Int. J. Biol. Macromol. 2011, 49, 1143-1151. [CrossRef] [PubMed]

36. Cao, J.G.; Xia, X.; Chen, X.F.; Xiao, J.B.; Wang, Q.X. Charactetization of flavonoids from Dryopteris erythrosora and evaluation of their antioxidant, anticancer and acetylcholinesterase inhibition activities. Food Chem. Toxicol. 2013, 51, 242-250. [CrossRef] [PubMed]

37. Zhu, K.; Zhou, H.; Qian, H. Antioxidant and free radical-scavenging activities of wheat germ zsprotein hydrolysates (WGPH) prepared with alcalase. Process Biochem. 2006, 411, 296-302.

Sample Availability: Samples of the compounds AnPS are available from the authors.

(C) 2018 by the authors. Licensee MDPI, Basel, Switzerland. This article is an open access article distributed under the terms and conditions of the Creative Commons Attribution (CC BY) license (http:/ / creativecommons.org/licenses/by/4.0/). 